\title{
BMJ Open Identity construction in medical student stories about experiences of disgust in early nursing home placements: a dialogical narrative analysis
}

\author{
Sally Warmington, ${ }^{1}$ May-Lill Johansen $\left(\mathbb{D},{ }^{2}\right.$ Hamish Wilson ${ }^{3}$
}

To cite: Warmington S, Johansen M-L, Wilson $\mathrm{H}$ Identity construction in medical student stories about experiences of disgust in early nursing home placements: a dialogical narrative analysis. BMJ Open 2022;12:e051900. doi:10.1136/ bmjopen-2021-051900

- Prepublication history for this paper is available online. To view these files, please visit the journal online (http://dx.doi. org/10.1136/bmjopen-2021 051900).

Received 31 March 2021 Accepted 31 January 2022

Check for updates

(C) Author(s) (or their employer(s)) 2022. Re-use permitted under CC BY-NC. No commercial re-use. See rights and permissions. Published by BMJ.

${ }^{1}$ Melbourne School of Population and Global Health, The University of Melbourne, Melbourne, Victoria, Australia

${ }^{2}$ Research Unit for General Practice, Department of Community Medicine, UiT The Arctic University of Norway, Tromso, Norway

${ }^{3}$ Otago Medical School, University of Otago, Dunedin, New Zealand

Correspondence to Dr May-Lill Johansen; May-Lill.Johansen@uit.no

\section{ABSTRACT}

Objectives To explore medical students' reflective essays about encounters with residents during preclinical nursing home placements.

Design Dialogical narrative analysis aiming at how students characterise residents and construct identities in relation to them.

Setting Medical students' professional identity construction through storytelling has been demonstrated in contexts including hospitals and nursing homes. Some preclinical students participate in nursing home placements, caring for residents, many living with dementia. Students' interactions with these residents can expose them to uncontained body fluids or disturbing behaviour, evoking feelings of disgust or fear.

Participants Reflective essays about experiences as caregivers in nursing homes submitted to a writing competition by preclinical medical students in New Zealand.

Results Describing early encounters, students characterised residents as passive or alien, and themselves as vulnerable and dependent. After providing care for residents, they identified them as individuals and themselves as responsible caregivers. However, in stories of later encounters that evoked disgust, some students again identified themselves as overwhelmed and vulnerable, and residents as problems or passive objects. We used Kristeva's concept of abjection to explore this phenomenon and its relationship with identity construction. Conclusions Providing personal care can help students identify residents as individuals and themselves as responsible caregivers. Experiencing disgust in response to corporeal or psychic boundary violations can lead to abjection and loss of empathy. Awareness of this possibility may increase students' capacity to treat people with dignity and compassion, even when they evoke fear or disgust. Medical education theory and practice should acknowledge and address the potential impact of strong negative emotions experienced by medical students during clinical encounters.

\section{INTRODUCTION}

Identity formation in medical education has been studied from multiple theoretical perspectives, leading to a more nuanced understanding of this complex phenomenon.

\section{Strengths and limitations of this study}

- This article explores identity construction in medical education from a perspective that characterises identity as multiple, dynamic and relational.

- The independent analysis of each essay by three researchers, followed by two rounds of in-depth, iterative dialogues broadened the interpretations.

- We show how encounters that involve the perceived violation of corporeal or psychic boundaries can evoke disgust in students, with an associated loss of empathy, and we offer an interpretation based on the idea of abjection, as described by Kristeva.

- The importance of abjection has been previously explored in relation to nursing practice and cadaver dissection, but we have demonstrated for the first time its relevance to clinical placements in medical education.

- Although this study used limited data from a small number of students from one medical school, there are broader implications indicating a need for further study of this topic in a variety of contexts.

This paper is based on a perspective that characterises identity as multiple, dynamic and relational. ${ }^{2-4}$ Identity construction through storytelling, including face-to-face encounters and reflective writing, is integral to all human interactions and has been demonstrated in educational contexts including school classrooms and teaching hospitals. ${ }^{5-7}$ Narrators often construct multiple identities, either within a single story or a series of related stories. These identities are influenced by the context in which an encounter takes place including the physical setting, the purpose of the encounter and the involvement of other people. ${ }^{89}$ Narrative-based activities have been introduced in medical education to facilitate learners' professional identity construction and their capacity for reflection. ${ }^{310}$

Some medical schools offer early placements that engage students in caregiving activities in hospitals or nursing homes. The 
intended benefits include providing insight into the social and cultural dimensions of healthcare, enhancing understanding of caregiving and promoting the early development of professional identities. ${ }^{11-14}$ Previous research has explored identity construction associated with caregiving placements. ${ }^{111215}$ This paper has a distinctive focus on the relationship between the identities that students constructed for themselves and their characterisations of nursing home residents. We chose to focus on students' stories that described feelings of disgust in relation to their care-giving tasks. Although medical students can at times feel revulsion, nausea or disgust in relation to specific patients, these powerful negative emotions have rarely been explored in medical education literature, and this paper addresses this deficit.

\section{Theoretical perspectives}

\section{Dialogue and relational identity}

Mikhail Bakhtin originated the idea of thinking about human relations as a dialogue. ${ }^{16}{ }^{17}$ According to this view, the construction of the self-analogous to identity-is an ongoing project that involves a creative struggle and is always accomplished in relation to others. ${ }^{16} \mathrm{~A}$ dialogical approach to narrative research involves identifying diverse voices and the meanings that emerge when they are juxtaposed or placed 'in dialogue' with each other. It highlights unique and seldom-heard voices as well as common experiences. ${ }^{18}$ We combined elements from several other researchers' approaches to produce the dialogical framework for our analysis. ${ }^{18-20}$

The process of dialogical narrative analysis allows the researcher to investigate how identity is constructed 'in the moment' in relation to others. Analysis can reveal how a narrator depicts and evaluates characters in a story as particular types of people, taking positions of support or disapproval in relation to their actions or perceived motivations. ${ }^{21}$ Alongside our analysis, the stories presented in this paper will show how this process works in practice.

Social theorist and psychoanalyst Julia Kristeva, informed by the work of Bakhtin and others, proposed a dynamic, relational view of the self which she named as 'le sujet en procès'. ${ }^{22}$ This term is ambiguous, meaning both in process and on trial; by characterising the human subject as being in-process-and-on-trial, Kristeva draws attention to the tension and struggle involved in the ongoing construction of identities in the interactions between people.

In this project, our use of the dialogical analytic approach to researching identity construction is congruent with its theoretical perspective: that identity is a social phenomenon that emerges through specific interactions between people. ${ }^{20}$ The identities revealed by this process are constructed in the moment, never fixed and constantly open to change.

\section{Abjection, disgust and unstable boundaries}

Kristeva used the term abjection to refer to a psychic defence mechanism employed in situations which evoke disgust, revulsion or fear. ${ }^{23}$ Abjection involves rejection or retreat from a person identified as abject, as a result of the perceived violation of expected corporeal or psychic boundaries of the observer, in a particular context. Such violations are experienced as a threat to the observer's 'clean and proper' self. Corporeal boundary violations include exposure to uncontained body fluids such as blood, vomitus, urine or faeces. Psychic boundaries may be perceived as being disrupted by behaviour that violates social norms, which can be associated with dementia or psychosis. The human corpse can also be perceived as abject because it represents in material form the boundary between life and death, reminding people of their own bodies' inevitable disintegration and decay. ${ }^{23}$ When students are exposed to the cadaver through dissection, it is viewed through the lens of science but it retains its power to elicit disgust and the psychic defence of abjection.

Kristeva argues that the powerful responses people often experience in response to a person perceived as abject are connected to the infant's earliest identification as a separate being from their mother. Early feelings of the abject are related to the expulsion of unwanted material from the infant's own body, such as faeces and vomitus. The abject has both symbolic and material dimensions, and because early associations leave traces in the subconscious mind, it can elicit powerful responses, even in adult life. ${ }^{24}$ Originating in the stage before language develops, it can be difficult for adults to identify, understand and express their later experiences of the abject, which is more often experienced viscerally in the body.

Disgust and the abject have received very limited attention in the medical education literature. An analysis of medical student narratives about their dissection of cadavers drew on psychoanalytic theory and abjection. ${ }^{25}$ It provided insight into the way physicians create emotional distance from cadavers-and their patients who may be approaching death. Although emotional defences serve a purpose, they have limits and often break down. Zwier argues that the provision of empathic care requires the physician to develop the capacity to encounter the abject without resorting to a distancing, biomedical lens.

Several researchers in the nursing literature have drawn on the idea of abjection to investigate healthcare contexts as diverse as dementia care, the HIV/AIDS epidemic, wound care and forensic psychiatry. ${ }^{24}{ }^{26}$ Health professionals are often exposed as a result of their work to situations that evoke disgust, revulsion or fear. Even though they are trained and socialised to offer help to those in their care, the psychic defence of abjection produces a desire to retreat from the person who evokes these feelings. ${ }^{26} 27$ Because there has been minimal published research in medical education exploring responses to disgust in clinical or caregiving encounters, students and their clinical teachers are unlikely to be aware that the resulting psychic defence of abjection can diminish their capacity for empathy and compassion and compromise the quality of their care. 


\section{METHODS}

\section{Participants and placement context}

The five participants in this study, three men and two women, were at the time of their placements secondyear medical students at the University of Otago in New Zealand and between 19 and 23 years of age. They each attended 20 hours of a nursing home placement over a 5-week period. During that time, they assisted people living in the home (hereafter referred to as residents) with their personal care: eating and drinking, dressing, bathing and toileting as well as social interaction. They were supervised by nurses or personal care attendants, referred to here as caregivers or staff members.

In preparation for their placements, participants had attended a lecture and group tutorials about dementia, dependency, frailty, end of life care and their caregiving role. The programme aimed to provide opportunities to learn about the social contexts of healthcare, to construct professional identity and to develop their capacity for reflection. ${ }^{13}$ After their attachments, students had a group debriefing and each submitted a reflective essay about their experiences. These activities provided opportunities to recall their interactions and attempt to make sense of them, with tutors' mentoring and feedback facilitating the articulation of their thoughts and feelings. ${ }^{28-30}$

\section{Data collection}

The essays analysed for this study were submitted to a reflective essay writing competition offered in 2015 by the Balint Society of Australia and New Zealand (BSANZ) to medical students in those countries. The competition was separate from their course and had no impact on their assessments, but submissions could be based on previously submitted coursework essays. Essays had to describe in English, in 1000-2000 words, first-hand encounters between the student and a patient or resident during their medical course. They were eligible to win cash prizes, publication opportunities or attendance at a BSANZ workshop. Written consent was obtained to analyse their writing for this research project from the authors of 22 of the 24 essays rated highest by the judging panel. After reviewing the settings and main themes of those essays, we chose to study in depth the five essays about nursing home placements. The students who submitted these essays all attended the medical school in which the third author is a faculty member.

\section{Dialogical narrative analysis}

The dialogical narrative analysis focused on three domains: the context in which a story was told; how it was produced and what was accomplished by telling it. These domains provided focal points for the analysis, and further layers of meaning emerged through the juxtaposition of stories. The method is outlined later and described in more detail elsewhere. ${ }^{67}$

Narrative context includes a consideration of how a story was elicited, since they are always told in response to something, such as a question or another story. Every story is designed for a particular audience, and in turn anticipates a response. ${ }^{18}$ The material analysed for this project was produced in answer to the call for entries to the writing competition, after the students' debriefing and feedback sessions for the nursing home placements.

Narrative production refers to the way meanings are constructed by way of the language forms and other narrative devices used by storytellers. ${ }^{19}$ Different forms of a given language, called speech genres or voices, are used by narrators to represent their own speech and that of other characters. Story characters are portrayed as certain kinds of people, either directly by description or indirectly through the words or actions attributed to them. One of the devices employed by narrators is called interactional positioning. ${ }^{21}$ This involves the narrator adopting a position in relation to characters by portraying them in certain ways and indicating their support or opposition to them. In using this device, narrators can identify themselves as belonging to the same social group as one of the characters in a story, and others as belonging to a different group. Narrative work refers to what is achieved by telling a particular story; in this case, we focused on the work of identity construction. ${ }^{18}$

We followed an iterative, interactive process for our analysis. As the first step, each of the three researchers analysed the five essays separately, using the method described earlier. Then, we discussed what had emerged from each person's analysis of single stories and of the series of stories in each essay. Common and unique interpretations were discussed and juxtaposed. Through these dialogues, representing a second level of analysis, insights emerged that had not come to light through the individual work.

After all the essays had been analysed in this way, each member of the team considered the body of essays as a whole, focusing on one of three topics of interest that emerged from the second level of analysis. These were: the changes in each student's characterisations of residents in the course of one essay; the construction of identity in relation to residents and staff; and students' interactions with suffering or dying residents. Each researcher's analysis of the whole body of material with a focus on one of these themes, and the subsequent discussion, represented a third level of analysis. This paper relates to the findings about identity construction in relation to students' characterisations of residents. Another paper has already been published about the students' encounters with suffering and dying residents in nursing homes, and the value of reflection on experience-based learning. ${ }^{31}$ All names in both papers are pseudonyms.

\section{Patient and public involvement}

Patients and/or the public were not involved in the design, or conduct, or reporting, or dissemination plans of this research.

\section{FINDINGS}

Although the students' experiences and responses to them were different from each other, all five essays 
contained shifts in the way students characterised residents and the identities they constructed for themselves. Some students initially perceived residents as being passive, like inanimate objects or alien creatures, identifying themselves as overwhelmed, dependent and childlike. Others recognised residents' humanity, but still were uncertain how to interact with them.

After becoming involved in their care, students characterised residents as individuals deserving respect and empathy. Many described a pivotal moment that led to a change in their perception of a particular resident, and in how they saw other residents as well. Through their more empathic characterisations of residents, they identified themselves as responsible and compassionate caregivers. However, some students subsequently wrote about encounters which evoked feelings of disgust. In these stories, residents were depicted as passive objects or problems to be solved, and students identified themselves as vulnerable and dependent on staff.

\section{Jim's stories}

Jim's first story relates his earliest caregiving experience at the nursing home, and reveals shifts in his characterisations of the resident, a staff member and himself. Jim is helping a staff caregiver to shower a woman resident who is blind. Writing about taking off her clothes, he says that he wondered what it would feel like to be in her situation, but when he sees her standing naked his perception changes.

Pale yellow folds of fat rolled lethargically as she moved to grab her walking frame. I remember thinking how much she looked like the cadavers we had cut into in the dissecting room; how closely the yellow tinge of her skin resembled that of those bodies on the table; of death. I am ashamed of that thought but it was all I could think of. I didn't feel scared or shocked. I felt almost numb, realising that death is the only thing we can depend on happening in life. ... We are all close to death in some way or another. That made me even more determined to ensure that this woman's dying days weren't spent in suffering.

Although he briefly compares her body to a cadaver, he then reverts to a more compassionate view, expressing his determination to help this woman towards the end of her life. Finally, he depicts the shower as a three-way struggle between the resident, the staff caregiver and himself.

We cooperated for the washing; I was directing the shower head and the caregiver with me was busy scrubbing her with a cloth. ... At one point, the old woman said lavishly to me, 'You're doing a much better job of this than her; she just wants to hurry and get it over with and doesn't take her time!' I looked at the caregiver and she appeared slightly disgruntled, replying, 'Well that's because you don't cooperate all the time!' as she continued scrubbing her roughly, as if she were an animal.
Jim identifies himself through this story as more compassionate and empathic than the staff member, who he considers is treating the resident as though she were less than human. This is an example of how some students construct identity: they may identify more closely with a resident by distancing themselves from staff when they do not approve of the way a caregiver has treated that resident.

Subsequently, however, Jim writes about having to change a man's continence pad in the toilet.

As I got the pad off by making tears in the sides, my senses were assaulted with the abhorrent stench of faeces. The inside of the pad was filled with it; a black, watery substance that looked horribly like cow dung. I felt like throwing up. I carefully held the pad, trying to make sure that none of the excrement fell out of it. This was to no avail. As I was carrying it to the bin, some fell out onto the linoleum floor with a disgusting 'splat'. I suddenly froze. I could feel that rising sense of panic that comes with an emotional resistance to a situation; the foul smell and sight of faeces, the withered old man muttering to himself on the toilet, oblivious to the battle inside me.

At this point in the story, Jim depicts the old man only as a problem, and does not consider whether embarrassment or shame could be contributing to his demeanour. He identifies himself as incompetent and vulnerable, then describes being helped by a staff member who makes him feel better about his reaction to the man's incontinence. She helps him to accept that mistakes happen in all aspects of healthcare, and that ... 'no matter how strong my emotional reaction to [a] mistake is, the most important thing is to keep going'. Although Jim writes that recognising his emotional reactions should help him be more 'empathetic, caring and competent' in his future practice, the man in this story is depicted as a problem rather than someone deserving empathy and compassion.

\section{Sean's stories}

Sean and one resident are characters in three stories about his time at a psycho-geriatric residential care ward. His opening story vividly evokes his first arrival on the ward, revealing his responses to the chaotic scene confronting him.

All of my senses were on high alert. ... A lady walked in front of me, whimpering. I crept tentatively towards the nurses' station. I felt completely overwhelmed. ... Residents from all around me stared, some made gestures, and others made incoherent mumblings. Many gazed blankly into space. I had never seen people like this before-they looked like empty shells ... I exchanged a couple of short pleasantries with the nurses to ground myself ...

An aggressive resident tried to hit a nurse ... peering straight into my eyes, he asked me 'do you think you're smart, I'll knock you out!' and then came 
towards me with an agitated expression.... He fought angrily as we dragged him back to his room.

In this story, Sean portrays the residents variously as frightening, as objects of pity or as lifeless discarded objects ('empty shells') while nursing staff are depicted as capable and a source of protection and guidance. Sean characterises himself as overwhelmed by emotion, like a vulnerable child. In this story, staff members are characterised as allies while residents are seen as objects of pity or fear.

Later, he describes how he engaged in the care of the same resident.

My first friend came in the form of the original whimpering lady; she was crying again, and I asked if I could take her for a walk. I was happy when the nurses accepted my request, as I desperately needed to regain my composure after the earlier incident. After a large hug, her tears ceased, and we sat down in front of a window overlooking the forest.

Sean's offer to help this woman is made for his own benefit as well as hers, and sharing a hug reminds him that they are both vulnerable human beings. After she stops crying, they chat about her love of painting, and sing numbers from 'The Sound of Music'. He draws a moving portrait of entering into a dialogue with her, aided by music and physical touch. However, after a while:

$[\mathrm{H}]$ er thoughts grew cloudy, her movements uncertain as the grip of dementia insidiously returned. ... I held her hand and took her back to the ward. ... I felt like I was looking after a child ... guiding her through the obstacles of life. It made me feel depressed but extremely important at the same time. At first, I had felt very afraid of the residents; their behaviours were so unpredictable that I was constantly vigilant in their presence. But now I no longer felt afraid; my artistic friend had given me this. She highlighted how incredibly unique the residents were.

As a result of engaging in her care, Sean has become capable of identifying this resident as a unique individual and responding to her in a competent and compassionate way. This can be interpreted as a meta-narrative charting the emergence of a mature and compassionate caregiver identity. Although we might expect this way of relating to residents to be reflected in subsequent stories, the reality is more complex. This is clearly demonstrated when Sean later tells how he has to help his 'artistic friend' go to the toilet when staff in the area leave to help a fallen resident.

She needed to go to the bathroom or else she'd 'explode'. While in the bathroom ... she started to go without restraint and in her pants. I was in absolute shock and the smell was unbearable. I felt like I was going to be sick. In a panic I lifted her up onto the toilet. I then shuddered when I realised I would be doing the wiping for her as well. ... Unnervingly, a six-foot-six resident then burst into the bathroom complaining of being unable to breathe. Meanwhile the now whimpering lady was trying to get off the toilet. I had to keep her on the toilet while simultaneously heaving the giant man back into the hallway.

Sean's description is focused on his visceral and emotional responses and the practical actions he has to take. He overcomes his resentment towards the caregivers for leaving him alone and unsupported by reflecting on their own lack of training.

I felt indignant for being left on my own to deal with this mess. But it occurred to me that many of the carers only had three orientation sessions before being thrown in the deep end. This was the life of a carer; I took a deep breath and went out to face the giant man.

Feeling overwhelmed, Sean struggles to overcome his revulsion and complete the tasks he is faced with. He identifies with the caregivers, despite their absence, while the residents are portrayed as problems to be solved or adversaries. In contrast with his earlier sensitive portrayal, there is little empathy expressed, either for the woman on the toilet or the man who can't breathe. It appears as though the exposure to uncontained faeces and a man who appears threatening-implied by the description 'giant man'-leads him to identify himself as helpless and child-like.

Even when he depicts himself later in the story as a responsible caregiver, the residents are characterised as problems to be solved rather than people in need of care. Like Jim in his story about a similar incident, Seán identifies strongly in this story with the caregiving staff. He is feeling overwhelmed, and staff members are seen as providing guidance and protection, although in his case they are not physically present.

\section{DISCUSSION}

These excerpts demonstrate the kinds of identity shifts that take place within stories and between stories in each essay. We perceived the series of stories in each student's essay as constructing a meta-narrative charting their developing maturity and competence through providing personal care to nursing home residents. This resulted in the construction of their identities as responsible caregivers, in some instances representing themselves as more compassionate than staff members.

We observed that this meta-narrative could be disrupted by subsequent stories of encounters in which students experienced disgust. Jim and Sean's stories of exposure to uncontained faecal incontinence which they had to clean up were notably lacking in expressions of empathy or respect for the residents involved. The inclusion of these stories is particularly interesting in the context of the essay competition, in which students could be expected to depict themselves in a positive light. In addition, an encounter with a person experiencing 
faecal incontinence is not a topic that would usually be considered narratable — worthy of being told in a story. ${ }^{18}$ However, several students did choose to tell stories about these experiences, perhaps because of the powerful effect they had on them and the way the call for reflective essays was framed.

As Kristeva describes, abjection is a psychic defence mechanism of rejection or avoidance that can occur in response to a perceived disruption of corporeal boundaries, of which exposure to uncontained human waste is one instance. These students' encounters with residents experiencing faecal incontinence are typical situations which could result in a person being seen as abject, evoking visceral and emotional responses such as those described by James and Sean. In these stories they characterised the residents involved as problems to be dealt with, or as passive objects. They did not appear to be aware that experiencing disgust in response to a resident could diminish their own capacity to consider that person's experience and to behave compassionately towards them.

A critical discourse analysis of the medical education literature was undertaken by McNaughton ${ }^{32}$ to identify different discourses used in relation to emotions, and their implications, concluding that there was a need to address emotion more explicitly in medical training. The link between medical students' identity construction and emotions has also been acknowledged, along with the importance of learning to recognise and manage emotions more effectively. Although the paper by Zwier ${ }^{25}$ introduces the theory of abjection in relation to cadaver dissection, the medical education literature has yet to address the emotion of disgust and the response of abjection in the context of clinical placements, which are the focus of this paper.

With the very limited medical education literature on disgust and the abject, the nursing literature provides pertinent material to inform discussion about our findings. Although nurses are trained and socialised not to show emotions like disgust or revulsion in their professional interactions, they can still experience them in response to the abject. ${ }^{24}$ Suppressing or denying negative feelings such as fear, disgust, anger or humiliation can have detrimental effects on the health of nurses and other caregivers, leading to despair, helplessness and a perception that their work is meaningless. ${ }^{27}$ This can have a negative impact on the quality of the care they provide. Strategies nurses employ to safeguard personal boundaries, such as deploying a 'professional persona' or creating 'safe zones' can heighten their anxiety and lead them to focus more on personal protection than the care of the person with dementia. ${ }^{27}$ Nurses' health and well-being could be enhanced, along with the quality of care for people with dementia, if negative feelings like fear or repulsion could be dealt with openly, for example through supervision or peer support, instead of being disavowed or repressed..$^{2733}$

These findings are consistent with recommendations made by other authors in relation to medical education. ${ }^{42}$ Medical students also operate in a social context in which experiences of abjection are disavowed. Acknowledging these experiences and understanding how boundaries work in professional practice would help students deal with distressing encounters. This awareness may be helpful for them as well as for those people they are looking after.

\section{Reflexivity, strengths and limitations}

Although the essays were written before the start of the project, we considered factors that might have influenced their content. Students may have had certain assumptions about what kinds of stories the judging panel would consider desirable. Since we only had access to the most highly rated essays, another bias exists related to the kinds of stories the competition panel preferred. This is one limitation of the project which could be addressed in future research by studying identity formation in stories that were not produced for a competition or selected by a judging panel.

Throughout the project, the researchers considered and discussed the potential for our own subject positions to influence its outcomes. The third author is a medical doctor, senior faculty member and cocurator of the reflective writing competition. He designed the programme at the medical school in New Zealand which included the participants' residential care placements. This could have produced a bias in favour of positive evaluations of the placement experience. The first and second authors are medical doctors and researchers associated with medical schools in Australia and Norway, respectively. They had no contact with the participants, but the first author was a member of the judging panel for the essay competition. We acknowledge that our perspectives and prior experiences were likely to influence our interpretations of the narrative material. The independent analysis of each essay followed by two rounds of in-depth, iterative dialogues broadened the interpretations, which might otherwise have been limited by a single perspective.

\section{CONCLUSION}

By analysing early medical students' reflective writing about a nursing home placement, we have shown how students constructed identities for themselves through their shifting characterisations of residents and how they positioned themselves in relation to them. Notably, they depicted themselves as responsible and compassionate caregivers after engaging in the personal care of residents, characterising them as unique individuals. We also showed how encounters that involved the perceived violation of corporeal or psychic boundaries can evoke disgust in those same students, with an associated loss of empathy. We have offered an interpretation of these responses based on the idea of abjection, as described by Kristeva. Experiencing disgust in the face of the abject, students who had previously constructed responsible and compassionate caregiver identities subsequently depicted 
themselves as overwhelmed and dependent. The importance of abjection has been previously explored in relation to nursing practice and cadaver dissection ${ }^{2425} 27$ but we have demonstrated for the first time its relevance to clinical placements in medical education.

This research offers a way to guard against the threat to people whose physical or mental impairments tend to evoke revulsion or disgust in caregivers: that as a result, those caregivers can respond with distancing, rejection and a lack of empathy towards them. If clinical educators, students and clinicians are aware that the psychic defence mechanism of abjection can affect their own responses in such situations, they will be more likely to recognise them when they occur. As a result, both students and experienced clinicians should be better prepared to offer compassionate care, because they may be able to direct their attention to the experience of the person perceived as abject while recognising their own emotional responses. This has the potential to strengthen students' identities as responsible caregivers and enhance the quality of their clinical encounters.

Although this study used limited data from a small number of students from one medical school who reflected on their nursing home placements, there are broader implications indicating a need for further study of this topic in a variety of contexts. It is vital for the quality of clinical or caregiving encounters, both during medical education and beyond, that emotions such as disgust and fear evoked by certain kinds of encounters are recognised and their potential detrimental impacts acknowledged. Pedagogical advances in this area could incorporate a basic understanding of the theory of abjection for both teachers and learners, offering the potential for improved quality of care in subsequent clinical encounters during which they experience strong negative emotions.

Acknowledgements The authors are grateful to the students who provided their reflective writing for this study and to residents and staff of the nursing homes who participated in their learning.

Contributors HW had the idea for the study, wrote the proposal and acted as guarantor. SW suggested the analytic approach and theoretical perspective. HW, SW and M-LJ discussed the design of the study and contributed equally to the analysis. SW wrote the manuscript draft, which was iteratively discussed, modified and finally approved by HW and M-LJ.

Funding The authors have not declared a specific grant for this research from any funding agency in the public, commercial or not-for-profit sectors.

Competing interests None declared.

Patient consent for publication Not applicable.

Ethics approval This study involves human participants and was approved by University of Otago Human Ethics Committee (Category B, approval D16/304). Participants gave informed consent to participate in the study before taking part.

Provenance and peer review Not commissioned; externally peer reviewed.

Data availability statement No data are available. Our data are essays written by medical students. Publication of these is not included in the students' informed consent.

Open access This is an open access article distributed in accordance with the Creative Commons Attribution Non Commercial (CC BY-NC 4.0) license, which permits others to distribute, remix, adapt, build upon this work noncommercially, and license their derivative works on different terms, provided the original work is properly cited, appropriate credit is given, any changes made indicated, and the use is non-commercial. See: http://creativecommons.org/ licenses/by-nc/4.0/.

ORCID iD

May-Lill Johansen http://orcid.org/0000-0003-3623-0089

\section{REFERENCES}

1 Monrouxe L, Rees E. Theoretical Perspectives on Identity: Researching identities in medical education. In: Cleland J, Durning SJ, eds. Researching medical education. Oxford: John Wiley \& Sons, 2015.

2 Barr J, Bull R, Rooney K. Developing a patient focussed professional identity: an exploratory investigation of medical students' encounters with patient partnership in learning. Adv in Health Sci Educ 2015;20:325-38.

3 Clandinin DJ, Cave M-T. Creating pedagogical spaces for developing doctor professional identity. Med Educ 2008;42:765-70.

4 Dornan T, Pearson E, Carson P, et al. Emotions and identity in the figured world of becoming a doctor. Med Educ 2015;49:174-85.

5 Wortham S. Learning identity: the joint emergence of social identification and academic learning. New York: Cambridge University Press, 2006.

6 Warmington S, McColl G. Medical student stories of participation in patient care-related activities: the construction of relational identity. Adv Health Sci Educ Theory Pract 2017;22:147-63.

7 Warmington SG. Storytelling encounters as medical education: crafting relational identity. Abingdon: Routledge, 2020.

8 de Fina AE, Schiffrin DE, Bamberg ME. Discourse and identity. Cambridge: Cambridge University Press, 2006.

9 ledema R, Caldas-Coulthard C. Introduction. In: ledema R, CaldasCoulthard C, eds. Identity trouble: critical discourse and contested identities. Houndmills: Palgrave-Macmillan, 2016.

10 Nevalainen MK, Mantyranta T, Pitkala KH. Facing uncertainty as a medical student--a qualitative study of their reflective learning diaries and writings on specific themes during the first clinical year. Patient Educ Couns 2010;78:218-23.

11 Scavenius M, Schmidt S, Klazinga N. Genesis of the professionalpatient relationship in early practical experience: qualitative and quantitative study. Med Educ 2006;40:1037-44.

12 Helmich E, Derksen E, Prevoo M, et al. Medical students' professional identity development in an early nursing attachment. Med Educ 2010;44:674-82.

13 Perez D, Rudland J, Wilson $\mathrm{H}$. The revised early learning in medicine curriculum at the University of Otago - focusing on students, patients, and the community. NZ Med J 2009;122:1292.

14 Davison E, Lindqvist S. Medical students working as health care assistants: an evaluation. Clin Teach 2020;17:382-8.

15 Helmich E, Bolhuis S, Prins J, et al. Emotional learning of undergraduate medical students in an early nursing attachment in a hospital or nursing home. Med Teach 2011;33:e593-601.

16 Holquist M. Dialogism: Bakhtin and his world. London and New York: Routledge, 2003.

17 Bell M, Gardiner ME. Bakhtin and the human sciences: no last words. London: Sage, 1998.

18 Frank AW. Letting stories breathe: a Socio-Narratology. Chicago: University of Chicago Press, 2010.

19 Gubrium JF, Holstein JA. Analyzing narrative reality. Los Angeles: Sage, 2009.

20 Riessman CK. Narrative methods for the human sciences. Los Angeles, Ca: Sage, 2008.

21 Wortham SE. Interactional positioning and narrative selfconstruction. Narrative Inquiry 2000;10:157-84.

22 Kristeva J, Guberman RM. Julia Kristeva interviews. New York: Columbia University Press, 1996.

23 Kristeva J. Powers of horror. New York and Oxford: Columbia University Press, 1982.

24 Holmes D, Perron A, O'Byrne P, O’Byrne P. Understanding disgust in nursing: abjection, self, and the other. Res Theory Nurs Pract 2006;20:305-16.

25 Zwier RK. Slicing through thin layers of humanity: narratives of the abject. J Med Humanit 2020;41:501-13.

26 Rudge T, Holmes D, eds. Abjectly boundless: boundaries, bodies and health work. Ashgate: Surrey, 2010.

27 Holmes D, Lauzon S, Gagnon M. Encountering the Other: Nursing, Dementia Care and the Self. In: Rudge T, Holmes D, eds. Abjectly Boundless: bodies, boundaries and health work. Surrey, UK: Ashgate Publishing Ltd, 2010. : 245-56p.. 
28 DasGupta S, Charon R. Personal illness narratives: using reflective writing to teach empathy. Acad Med 2004;79:351-6.

29 Kind T, Everett VR, Ottolini M. Learning to connect: Students' reflections on doctor-patient interactions. Patient Educ Couns 2009;75:149-54

30 Nevalainen MK, Mantyranta T, Pitkala KH. Facing uncertainty as a medical student $-\mathrm{A}$ qualitative study of their reflective learning diaries and writings on specific themes during the first clinical year. Patient Educ Couns 2010;78:218-23.
31 Wilson $\mathrm{H}$, Warmington S, Johansen M-L. Experience-Based learning: junior medical students' reflections on end-of-life care. Med Educ 2019;53:687-97.

32 McNaughton N. Discourse(s) of emotion within medical education: the ever-present absence. Med Educ 2013;47:71-9.

33 Clarke N. Developing emotional intelligence through workplace learning: findings from a case study in healthcare. Human Resource Development International 2006;9:447-65. 